\title{
Analisis Reliability Centered Maintenance (RCM) Rel Conveyor pada Mesin Oven BTU Pyramax 150N di PT. Flextronics Teknology Indonesia - Batam
}

\section{Analysis of Realibility Centered Maintenance (RCM) Rail Conveyor on BTU Pyramax 150N Oven Machine at PT. Flextronics Teknology Indonesia - Batam}

\author{
Sariyusda* \\ Jurusan Teknik Mesin, Politeknik Negeri Lhokseumawe, Indonesia \\ *Corresponding author: E-mail: sariyusda@yahoo.com
}

\begin{abstract}
Abstrak
Reliability Centered Maintenance (RCM) atau lebih dikenal dengan the expert system of maintenance merupakan suatu metode desain sistem manajemen perawatan yang mampu memberikan jaminan ketersediaan, keselamatan, lingkungan serta desain sistem applicable dan komprehensif. Rel conveyor oven Btu Pyramax 150N adalah salah satu bagian yang sangat berpengaruh pada proses manufacturing sebuah PCB (Papan Circuit board) pada PT.Flextronics Teknology Indonesia - Batam (Indonesia). Tujuan yang ingin dicapai ialah melakukan perancangan sistem manajemen perawatan berdasarkan RCM untuk menghindari terjadinya kegagalan (failure) peralatan mesin pada saat operasi yang menyebabkan terganggunya produksi dapat dihindari. Metode yang dilakukan pada penelitian ini mengunakan metode FMEA (Failure Mode and effect analysis) dan penelitian dapat tiga peralatan kritis yaitu rantai conveyor, jaring baja dan alur poros melintang
\end{abstract}

Kata Kunci: Failure, Conveyor, FMEA (Failure Mode and effect analysis), Reliability Centered Maintenance (RCM)

\begin{abstract}
Reliability Centered Maintenance (RCM) or better known as the expert system of maintenance is a method of maintenance management system design that can provide guarantee of availability, safety, environment and system design applicable and comprehensive. Conveyor rail Btu Pyramax $150 \mathrm{~N}$ oven is one of the most influential parts in the manufacturing process of a PCB (Board Circuit board) at PT. Flextronics Teknology Indonesia - Batam (Indonesia). The goal to be achieved is to design the maintenance management system based on RCM is to avoid the occurrence of failure of machine equipment at the time of operation causing the production disruption can be avoided. The method used in this research using FMEA (Failure Mode and Effect Analysis) method. The result of the research is there are three critical equipments that are conveyor chain, steel net, and transverse shaft
\end{abstract}

Keywords: Failure, Conveyor, FMEA (Failure Mode and effect analysis), Reliability Centered Maintenance (RCM).

How to Cite: Sariyusda (2018), Analisis Reliability Centered Maintenance (RCM) Rel Conveyor pada Mesin Oven BTU Pyramax $150 N$ di PT. Flextronics Teknology Indonesia - Batam, JMEMME Uournal of Mechanical Engineering, Manufactures, Materials And Energy), 2 (1): 33-42 


\section{PENDAHULUAN}

Pada dunia industri yang semakin tinggi tingkat kompetitif saat ini, tuntutan akan kompetisi, efektifitas dan efisiensi semakin meningkat menuntut adanya peningkatan availabilitas (tingkat ketersediaan) peralatan untuk mendukung proses produksi (Stapelberg, 2009). Sehingga diperlukan desain sistem perawatan yang baik sebagai pendukung proses produksi. Oleh karena itu perancangan sistem perawatan mutlak dibutuhkan, dimana desain sistem perawatan yang terbaik adalah desain yang berorientasi pada jaminan kehandalan peralatan (American Bureau of Shipping, 2003) (Navaair, 2003).

Perawatan merupakan faktor yang sangat penting untuk mempertahankan kemampuan dan kehandalan mesin yang bertujuan untuk menjamin bahwa suatu sistem produksi dapat berlangsung secara fungsional. Perawatan sudah lama dikenal dan dilaksanakan, namun pengelolaannya belum mampu mengimbangi perubahan dan perkembangan ilmu pengetahuan dan teknologi (IPTEK) (Daryus, 2007).

Reliability Centered Maintenance (RCM) yang sering diartikan sebagai the expert system of maintenance adalah suatu metodologi dalam perencanaan perawatan yang bertujuan untuk menjaga sistem secara keseluruhan agar dapat berfungsi sesuai dengan tingkat performansi yang diinginkan (Moubray, 1997). Usaha dalam mempertahankan fungsi peralatan tersebut meliputi semua kebutuhan yang diperlukan pada manajemen perawatan, dalam ruang lingkup pengoperasian peralatan. Nilai tambah yang dapat diambil dari aplikasi dan pendekatan metode ini adalah kemampuannya dalam mengembangkan manajemen resiko yang komprehensif dan mampu mengkalkulasi setiap failure baik evident maupun yang hidden (B, 2006).

PT. Flextronics Technolgy Indonesia merupakan perseroan terbatas (PT) yang berlokasi di daerah kawasan Perindustrian Batamindo, BIP (Batam Industri Park).

Untuk tercapai Index Produktivitas Produksi (IPP) atau target produksi yang telah direncanakan perusahaan, PT Flextronics Teknology Indonesia sering melakukan overtime dari jam kerja normal mesin yang telah ditetapkan perusahaan. Hal ini disebabkan diantarnya:

a. Tidak tersedianya suku cadang di gudang untuk komponen/ peralatan yang mengalami kerusakan/kegagalan untuk dilakukan replacement sehingga membutuhkan waktu yang relatif lama untuk proses pengorderan yang mengakibatkan terganggunya jadwal perencanaan perawatan dan berujung pada terhentinya proses produksi.

b. Team maintenance melakukan kegiatan perawatan ketika kondisi peralatan atau komponen sudah mengalami kegagalan/kerusakan yang serius.

c. Ketidak presisian Rel conveyor dari Input Ke Output mengakibatkan problem conveyor dapat menjadi lebih besar.

Solusi yang ditempuh perusahaan untuk mencapai target produksi adalah menambah jam kerja karyawan (lembur) dan melakukan overtime terhadap mesin untuk mengejar target yang telah ditetapkan pada jadwal (A., 1992). Hal ini berdampak pada menurunnya performance mesin pada Conveyor. Solusi tersebut dilakukan untuk menjaga kelangsungan supply kepada pelanggan 
serta menjaga reputasi perusahaan dimata konsumen. Berdasarkan fenomena diatas, maka akan dilakukan penelitian dengan mendesain sistem perawatan yang baik berdasarkan Reliability Centered Maintenance (RCM) . Reliability Centered Maintanance (RCM) merupakan salah satu metode pemeliharaan mesin atau peralatan (Department of Defense United Stated of America, 1980). Rel conveyor adalah salah satu bagian yang sangat berpengaruh pada penentuan inti dari kwalitas suatu PCB yang telah dilakukan proses pengovenan didalam BTU pyramax ke seluruh projek yang telah di mounting pada mesin NXT. Masalah yang akan diselesaikan dalam penelitian ini berkaitan dengan pengembangan sistem perawatan pada PT. Flextronics Teknology Indonesia dalam usahanya untuk membuat suatu perencanaan sistem perawatan yang sesuai dengan karakteristik mesin yang ada. Beberapa permasalahan yang ingin dibahas dalam penelitian ini yaitu:

1. Sistem atau peralatan kritis dalam pelaksanaan proses produksi.

2. Alternatif kegiatan perawatan terhadap mesin atau peralatan kritis tersebut.

3. Ketidak Presisian Input Conveyor dengan Output Conveyor

Penelitian dilakukan memiliki

beberapa tujuan, antara lain:

a. Menganalisa permasalahan yang terjadi pada rel conveyor mesin oven BTU pyramax $150 \mathrm{~N}$.

b. Menentukan kegiatan perawatan yang harus dilakukan dalam mengantisipasi kemungkinan failure tersebut.

c. Menentukan jadwal dan prosedur perawatan yang optimal.

Batasan dan asumsi yang akan difokuskan hanya pada Conveyor Oven di
Line produksi dan asumsi Failure peralatan atau komponen yang terjadi yaitu yang tercatat pada data historis perawatan bukan disebabkan oleh faktor kesalahan manusia (human error) (Dhilon, 2006).

\section{METODE PENELITIAN}

Penelitian ini dilaksanakan di PT. Flextronics Teknology Indonesia berlokasi di daerah kawasan Perindustrian Batamindo ,BIP (Batam Industri Park) Jl. Rambutan Lot. 515 Muka Kuning, Batam 29433 Indonesia. Penelitian ini dilaksanakan dari pengumpulan data, wawancara langsung disertai dengan mereview dokumen-dokumen perusahaan yang berkaitan dengan tujuan penelitian ini.

Berdasarkan sifatnya, maka penelitian ini digolongkan sebagai penelitian (Descriptif Research), yaitu penelitian yang berusaha untuk memaparkan pemecahan masalah terhadap suatu masalah yang ada sekarang secara sistematis dan faktual berdasarkan data-data. Jadi penelitian ini meliputi proses pengumpulan, penyajian dan pengolahan data.

Data masalah yang dimaksud adalah data semua bentuk kegagalan peralatan mesin selama dua tahun terakhir khususnya yang berakibat langsung terhadap penurunan produksi. Data yang dikumpulkan adalah sesuai dengan laporan yang ada di PT. Flektronics Teknologi Indonesia.

\section{Data Primer}

Dilakasanakan dengan teknik observasi dan wawancara yaitu mengunjungi dan melakukan pengamatan langsung terhadap operasional dan perlengkapan peralatan PT. Flektronics Teknologi Indonesia serta melakukan wawancara langsung dengan para teknisi 
pada setiap tempat proses kerja untuk mendapat informasi yang diperlukan, termasuk:

1. Tingkat kegagalan peralatan mesin.

2. Jumlah penurunan produksi akibat kegagalan peralatan.

3. Jenis kerusakan penyebab penurunan produksi.

\section{Data Skunder}

1. Mereview laporan administrasi PT. Flextronics Teknology Indonesia seperti laporan mingguan, bulanan dan tahunan serta referensi perusahaan yang berhubungan dengan penelitian.

2. Menelaah buku-buku dan jurnal-jurnal penelitian yang berkaitan dengan pengembangan sistem pemeliharaan peralatan industri serta teori lain yang tepat sebagai masukan dalam rangka pemecahan masalah sesuai dengan kondisi lapangan.

3. Melakukan pencairan informasi yang berhubungan dengan penelitian melalui browsing internet.

\section{Pengolahan Data dan Analisa Data}

Data yang dikumpulkan kemudian diolah untuk dapat digunakan dalam penelitian. Tahapan pengolahan data yang dilakukan dalam penelitian ini adalah :

1. Menganalisa pemasalah yang terjadi pada conveyor

2. RCM Decision Worksheet

3. Menentukan jadwal strategi perawatan yang optimal.

\section{Menganalisa}

Rekomendasi tindakan yang didapat melalui pendekatan Reliability Centered Maintenance (RCM) yaitu:

a. Condition Directed (CD) yaitu tindakan yang diambil yang bertujuan untuk mendeteksi kerusakan dengan cara visual inspection, memeriksa alat dan memonitoring sejumlah data yang ada. Tindakan kategori ini mencapai 59\% berdasarkan pengelompokan komponen.

b. Failure Finding (FF) yaitu tindakan yang diambil dengan tujuan untuk menemukan kerusakan peralatan yang tersembunyi dengan pemeriksaaan berkala. Tindakan kategori ini mencapai $\quad 28 \% \quad$ berdasarkan pengelompokan komponen.

c. Run to Failure (RTF) yaitu ini bersifat korektif karena gejala mode kegagalan tidak dapat diidentifikasi. Tindakan kategori ini mencapai 13\% berdasarkan pengelompokan komponen.

Diagram alir metode pengujian yang dilakukan dalam pemecahan masalah dalam penelitian ini diperlihatkan pad gambar 1.

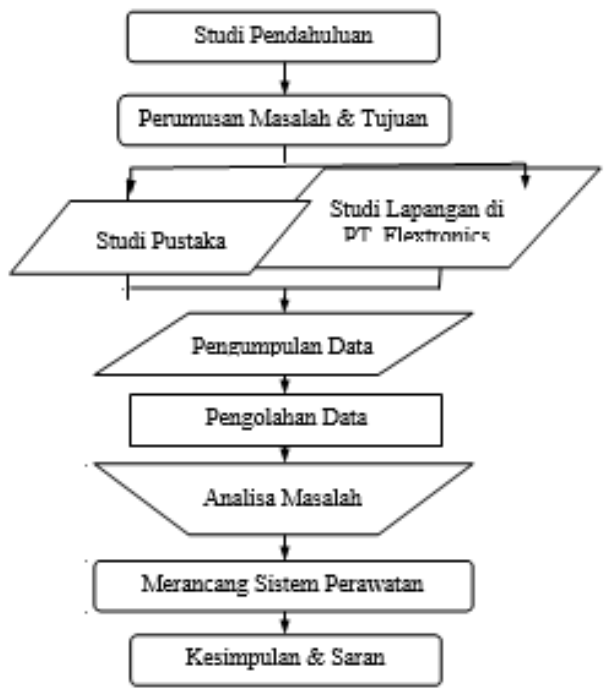

Gambar 1 Tahapan Proses Penelitian

Kegiatan Perawatan

Perancangan kegiatan perawatan yang dilakukan untuk peralatan Oven Btu 
pyramax adalah Analisis failure oleh beberapa engginer dari (menganalisi kegagalan), strategy PT.Flextronics, ini bertujuan agar maintenance conveyor (strategi yang perubahan yang dilakukan pada saat dilakkan untuk merawat conveyor) dan melakukan inovasi lebih terkontrol dan innovation schedul(Membuat inovasi dari tidak jauh melenceng seperti yang jadwal perawatan yang lama ke jadwal diharapkan.

perawatan yang baru) .

Kebijakan ini dapat dilakukan dengan batuan referensi dari strategi kegiatan yang sudah ditetapkan di PT.Flextronics technology Indonesia agar penerapan penentuan kegiatan perawatan yang dilakukan lebih maksimal karena hal ini bertujuan untuk mengembangkan strategy yang lebih maksimal lagi agar system perawatan maupun metode perawatan berjalan lebih maksimal. prosedur yang ada akan disesuaikan kembali sehingga akan mencegah terjadinya failure (Kegagalan) yang tidak di inginkan.

Prosedur Perawatan Optimal

Dalam menentukan prosedur perawan ini haruslah memiliki data perawatan yang sebelum nya yang ada pada PT.Flextronik Teknologi Indonesia karena dalam kasus ini kita akan membuat inovasi dari jadwal perawatan yang sudah diterapkan pada proses perawatan pada PT.Flextronics Teknology Indonesia, karena dengan begitu sebuah perencanaan inovasi prosedur perawatan yang lebih optimal akan lebih mudah diterapkan karena mempunyai referensi yang kuat dan sudah mengetahui apa kekurangan dari jadwal yang sudah diterapkan sebelumnya pada perusahaan tersebut.

Maka dengan hal ini prosedur ini dikukan juga atas batuan dari beberapa kasus yang pernah di didapatkan di Perusahaan ini, dan juga agar proses ini lebih mudah lagi pembuatan jadwal perawatan yang lebih optimal juga di bantu

\section{HASIL DAN PEMBAHASAN}

Pemilihan Peralatan Kritis

Dalam penelitian ini tidak semua peralatan akan dibahas, maka dipilih beberapa peralatan yang dianggap kritis dalam sistem. Pemilihan peralatan kritis ini didasarkan atas beberapa pertimbangan, antara lain:

a. Pengaruh failure operasi peralatan terhadap pemenuhan target produksi perusahaan. Dengan melihat sistem operasi yang dijalankan pada PT.Flextronics Teknology Indonesia terdapat 4 jenis kelompok peralatan yang ada dalam sistem, yaitu: Rantai conveyor, roda gigi pemutar conveyor, motor penggerak lebar kecilnya conveyor dan motor penggerak rantai. Rincian dari pembagian kelompok proses tersebut didasarkan atas fungsi dari masing-masing peralatan. Dapat diketahui bahwa yang memberikan pengaruh paling kritis terhadap tingkat kwalitas produk yang di hasilkan oleh oven BTU Pyramax. Sehingga jika terjadi failure pada peralatan-peralatan tersebut produksi akan terganggu, sehingga dapat diartikan terjadi penurunan target produksi perusahaan.

b. Banyaknya work order yang dilakukan pada peralatan yang mengalami kerusakan/kegagalan. Selama periode beroperasinya peralatan, berdasarkan informasi dan hasil wawancara dengan 
teknisi pada bagian maintenance peralatan yang memiliki frekuensi work order yang tertinggi ada pada bagian peralatan unit penggerak conveyor BTU Pyramax 150N.

Bagian ini menyajikan hasil penelitian. Hasil penelitian dapat dilengkapi dengan tabel, grafik (gambar), dan/atau bagan. Bagian pembahasan memaparkan hasil pengolahan data, menginterpretasikan penemuan secara logis, mengaitkan dengan sumber rujukan yang relevan. Hindari menggunakan sub bab jika memungkinkan. [Font: Cambria, size: 12 , normal, 1,15 spasi].

\section{Kegiatan Perawatan Pada Conveyor}

Pada unit Conveyor BTU Pyramax 150N terdapat 3 kegiatan perawatan yang dilakukan didalamnya sesuai dengan kebutuhan peralatan. Penjelasan dari kegiatan tersebut pada tabel 1 .

Tabel 1. Kegiatan Perawatan pada Conveyor

\begin{tabular}{|c|c|c|c|}
\hline Kegiatan & Diskripsi & Klasifikasi & $\begin{array}{c}\text { Kegiatan } \\
\text { Perawatan }\end{array}$ \\
\hline \multirow[t]{2}{*}{ Insepksi } & \multirow{2}{*}{$\begin{array}{l}\text { Pemeriksaan alat untuk } \\
\text { mengetahui apakah ada } \\
\text { failure fungsi atau tidak }\end{array}$} & Inspeksi visual & $\begin{array}{c}\text { Terjadwal dan } \\
\text { rutin }\end{array}$ \\
\hline & & $\begin{array}{l}\text { Inspeksi } \\
\text { kontrol }\end{array}$ & Rutin \\
\hline \multirow[t]{2}{*}{ Senvice } & \multirow{2}{*}{$\begin{array}{c}\text { Kegiatan untuk } \\
\text { mencapai standar yang } \\
\text { ditentukan (produksi dan } \\
\text { operasi) }\end{array}$} & $\begin{array}{c}\text { Waktu operasi } \\
\text { (easy failure) }\end{array}$ & Rutin \\
\hline & & $\begin{array}{c}\text { Stop (hard } \\
\text { failure) }\end{array}$ & Terjadwal \\
\hline \multirow[t]{2}{*}{ Repair } & \multirow{2}{*}{$\begin{array}{c}\text { Mengembalikan } \\
\text { kemampuan alat ke } \\
\text { kondisi semula atau } \\
\text { lebih baik }\end{array}$} & $\begin{array}{c}\text { Perbaikan } \\
\text { karena kondisi }\end{array}$ & $\begin{array}{c}\text { Terjadwal dan } \\
\text { rutin }\end{array}$ \\
\hline & & Pergantian & Terjadwal \\
\hline
\end{tabular}

Failure Mode and Effect Analysis (FMEA) Worksheets

FMEA merupakan salah satu teknik yang digunakan sebagai alat analisa tentang failure secara sistematis baik dari penyebab, dampak dan cara mendeteksi failure tersebut. Kolom fungsi menunjukkan fungsi yang dimiliki komponen, potential failure mode menunjukkan kegagalan, potential effect of failure menunjukkan apa yang terjadi jika komponen gagal memenuhi standar performansianya, potential cause menunjukkan mekanisme dari kegagalan, dan current process controls menunjukkan tindakan yang harus dilakukan dan menanggulanginya, serta dilakukan pembobotan severity, occurence, detection pada setiap komponen. Lihat pada tabel 2 FMEA Worksheets.

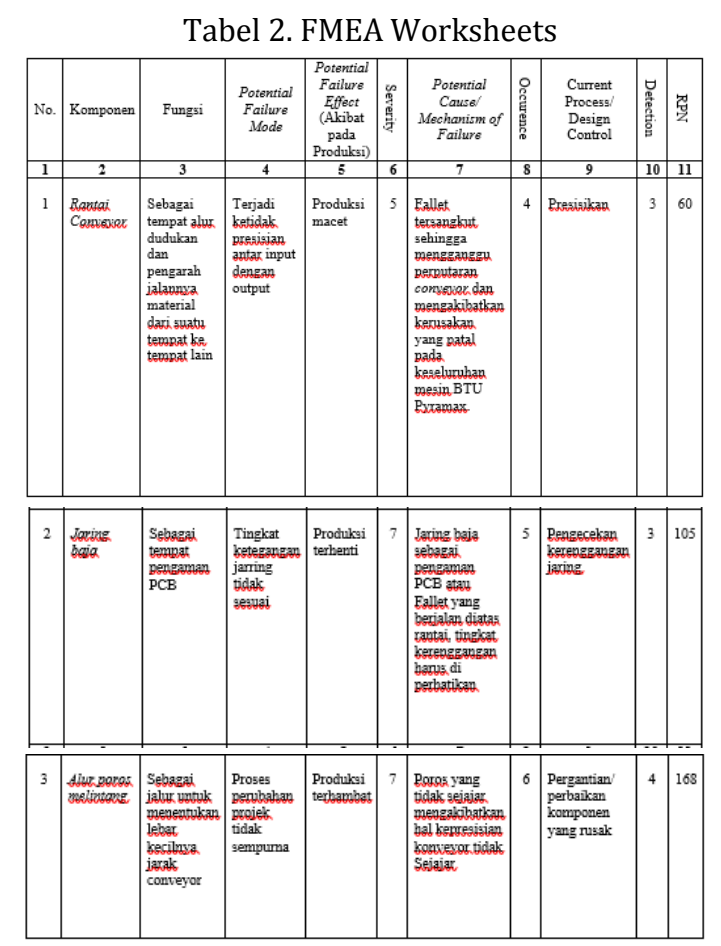

Berdasarkan FMEA yang dibuat untuk setiap komponen yang ada memiliki mode kegagalan yang berbeda satu dengan yang lainnya. Berdasarkan analisa FMEA, konsep ini dapat digunakan untuk merekomendasi tugas pemilihan komponen kritis yang memiliki derajat kegagalan yang lebih besar.

Sistem yang dapat digunakan untuk memantau komponen kritis pada unit Oven BTU pyramax $150 \mathrm{~N}$ terhadap kondisi perawatan berbasis pada kebijakan terhadap peningkatan penggunaan 
peralatan tersebut. Data tersebut dapat digunakan untuk peralatan dan nilai batas yang harus ditentukan sebagai indikator potensi kegagalan. Hasil identifikasi dapat memberikan informasi dalam menjadwalkan tugas-tugas pemeliharaan sebelum kegagalan fungsional terjadi. Analisa data berdasarkan kebijakan pelaksanaan perawatan harus direkomendasikan oleh RCM. Function failure yang terjadi pada conveyor disebabkan terjadinya penumpukan fallet dan PCB yang mengakibatkan motor penggerak tersangkut sehingga mengganggu jalannya pergerakan conveyor dan mengakibatkan terjadinya kemacetan produksi.

Pada Rantai Conveyor, kegagalan yang terjadi disebabkan akibat dari tingkat pengecekan rutin kurang dilakukan dan juga berpengaruh pada saat pergantian projek dari yang sebelumnya ke projek yang baru pada saat tingkat kecepatan laju rantai atau motor tidak stabil pada posisi putaran yang seharusnya, hal ini dapat mengakibatkan terhentinya proses produksi.

Pada jaring baja disebabkan akibat dari kurang nya tingakat kerenggangan dari pada jaring baja sebagai pengaman yang apabila PCB yang sudah diletakkan di atas rantai terjatuh maka jarring ini berfungsi sebagai pengaman dan apa bila pengaman ini tidak bekerja dengan maximal karena tingkat kerenggangan tidak disesuaikan maka mengakibatkan terhentinya produksi. RCM Decision Worksheet

RCM lebih menitik beratkan pada penggunaan analisa kualitatif untuk komponen yang dapat menyebabkan kegagalan pada suatu sistem yang dituangkan dalam bentuk failure mode and effect analysis (FMEA) dan RCM decision worksheet.

Tipe konsekuensi kegagalan dari Oven BTU Pyramax adalah failure dan operational consequence. Proposed task yang diharapkan perusahaan untuk masingmasing peralatan pada Oven BTU Pyramax adalah schedule on condition task dan failure finding.

Pada prinsipnya kegiatan perawatan schedule on condition task tersebut yaitu melakukan prediksi kegagalan atau mendeteksi/memeriksa terjadinya kegagalan potensial sehingga dapat menentukan tindakan untuk mencegah terjadinya functional failure atau menghindari konsekuensi dari functional failure dan selanjutnya diambil suatu langkah korektif setelah failure mode yang terjadi diketahui.

\section{Hubungan RPN dan Proposed Task}

Proposed task dipakai untuk mencatat jenis kegiatan perawatan yang terpilih dari alternatif kegiatan perawatan yang diadakan. Alternatif kegiatan yang perawatan yang menjadi pilihan adalah:

1. Schedule On Condition Task (SOCT), memerlukan kegiatan pemeriksaan terhadap potential failure sehingga tindakan yang diambil untuk mencegah functional failure. Penjadwalan dirancang dengan melihat kondisi peralatan yang ada.

2. Schedule Restoration Task, merupakan kegiatan pemulihan kemampuan awal komponen sebelum batas umur yang telah ditetapkan untuk memperhatikan kondisi nyata pada saat itu dengan melaksanakan minimal repair. 
Sariyusda, Analisis Reliability Centered Maintenance (RCM) Rel Conveyor pada Mesin Oven BTU Pyramax 150N di PT. Flextronics Teknology Indonesia - Batam

Perawatan ini dibuat untuk failure redesign pada kebijakan ini adalah mode dari failure ini hanya dicatat dan perancangan ulang dari kegiatan perawatan didokumentasikan oleh perusahaan. yang ada, prosedur yang ada akan

3. Schedule Discard Task, merupakan disesuaikan kembali sehingga akan tindakan mengganti item atau mencegah terjadinya failure.

komponen pada saat atau sebelum Kebijakan schedule on condition task batas umur yang ditetapkan tanpa adalah kegiatan pemeriksaan terhadap memperhatikan kondisi saat itu.

potential failure sehingga tindakan yang

4. Schedule Failure Finding Task, diambil untuk mencegah functional failure. merupakan kegiatan yang meliputi Penjadwalan dirancang dengan melihat tindakan checking (preventive kondisi peralatan yang ada.

maintenance) secara periodik atau Kebijakan failure finding diterapkan dengan interval waktu tertentu yaitu dengan melakukan kegiatan terhadap fungsi yang tersembunyi preventive maintenance secara periodik untuk mengetahui apakah komponen yang terjadwal. Dengan adanya kebijakan ini tersebut rusak atau tidak. Dengan maka akan ditemukan failure yang terjadi kebijakan ini maka akan ditemukan sehingga dapat mencegah efek yang timbul failure yang terjadi sehingga dapat akibat failure tersebut.

mencegah efek yang timbul akibat dari failure tersebut.

Strategi perawatan yang digunakan untuk perawatan conveyor ini adalah:

5. Redesign, merupakan kebijakan perancangan ulang dari kegiatan perawatan yang ada, dimana prosedur yang ada akan disesuaikan kembali sehingga akan mencegah terjadinya failure.

6. No Schedule Maintenance, kegiatan yang dilakukan apabila kegiatan yang terjadwal tidak dapat untuk mengetahui hidden function dan kerusakan yang terjadi tidak berakibat pada keselamatan lingkungan.

\section{Perancangan Kebijakan Perawatan}

Perancangan kebijakan perawatan yang dilakukan untuk peralatan Oven BTU pyramax adalah Analisis failure, strategy maintenance conveyor dan innovation schedule .

Kebijakan redesign, schedule on condition task dan failure finding dilakukan pada peralatan BTU pyramax 150N. Maksud

\section{a. Preventive Maintenance}

Berikut ini adalah uraian jenis pekerjaan yang dilakukan dalam ruang lingkup preventive maintenance, (Tabel 3).

Tabel 3. Preventive Maintenance

\begin{tabular}{|c|c|c|c|c|}
\hline No & Uraian & Tindakan & \begin{tabular}{|l|} 
Pexiode \\
\end{tabular} & Ruiukan \\
\hline 1 & $\begin{array}{l}\text { Remeriksaan } \\
\text { dan } \\
\text { pengechekan } \\
\text { putaran } \\
\text { motor }\end{array}$ & $\begin{array}{|lr|}\text { Memeriksa } & \text { dan } \\
\text { mengatur kecepatan } \\
\text { pada conveyor megin } \\
\text { BTU pxxamax } 150 \mathrm{~N} \text {, } \\
\text { kecepatan putaran } \\
\text { motor dan iarak } \\
\text { kereyggangan rantai } \\
\text { maunum pengaman }\end{array}$ & Harian & $\begin{array}{c}\text { Manual } \\
\text { book }\end{array}$ \\
\hline 2 & $\begin{array}{l}\text { Remeriksaan } \\
\text { dan } \\
\text { pengechekan } \\
\text { lebar } \\
\text { conveyor }\end{array}$ & \begin{tabular}{|lr} 
Memeriksa & dan \\
mengechek & lebar \\
jarak conveyor & pada \\
setiag & pergantian \\
proiek &
\end{tabular} & Harian & $\begin{array}{l}\text { Lapangan } \\
\text { dan } \\
\text { Jeknisi }\end{array}$ \\
\hline 3 & $\begin{array}{l}\text { Pemeriksaan } \\
\text { dan } \\
\text { pengechelan } \\
\text { pelumasan }\end{array}$ & $\begin{array}{l}\text { Demeriksa dan } \\
\text { mengechek kembali } \\
\text { jumlah pelumasnxa. }\end{array}$ & Harian & $\begin{array}{l}\text { Manual } \\
\text { book dan } \\
\text { Jeknisi }\end{array}$ \\
\hline
\end{tabular}




\section{b. Predictive Maintenance}

Berikut ini adalah uraian jenis pekerjaan yang dilakukan dalam ruang lingkup predictive maintenance, (Tabel 4).

Tabel 4. Prodictive Maintenance

\begin{tabular}{|c|c|c|c|c|}
\hline No & Uraial & Tindakan & Periode & Ruiukan \\
\hline 1 & $\begin{array}{l}\text { Remeriksaan } \\
\text { dan } \\
\text { pengecelan } \\
\text { Kalibrasi } \\
\text { Conveyor }\end{array}$ & $\begin{array}{l}\text { Mengkalibrasi conveyor } \\
\text { dengan menggunakan } \\
\text { alat - alat kalibrasi } \\
\text { megin conveyor BTU } \\
\text { puтатах } 150 \mathrm{n} \text {. }\end{array}$ & Bulanan & $\begin{array}{c}\text { Manual } \\
\text { book dan } \\
\text { teknisi } \\
\text { dilapangan }\end{array}$ \\
\hline 2 & $\begin{array}{l}\text { Remeriksaan. } \\
\text { pembersihan. } \\
\text { dan } \\
\text { pengechekan } \\
\text { belt and } \\
\text { drive system }\end{array}$ & 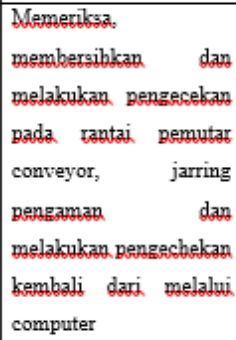 & Bulanan & $\begin{array}{c}\text { Manual } \\
\text { book dan } \\
\text { kondisi } \\
\text { lapangan }\end{array}$ \\
\hline
\end{tabular}

\section{c. Breakdown Maintenance}

Berikut ini adalah uraian jenis pekerjaa yang dilakukan dalam ruang lingkup breakdown maintenance (Tabel 5).

Tabel 5. Breakdown Maintenance

\begin{tabular}{|c|c|c|c|}
\hline No & Objek & Tindakan & Rujukan \\
\hline 1 & $\begin{array}{l}\text { Pengantian } \\
\text { rantai } \\
\text { conveyor } \\
\text { yang } \\
\text { rusak. }\end{array}$ & $\begin{array}{l}\text { Penggantian rantai } \\
\text { apabila rantai } \\
\text { pemutar conveyor } \\
\text { mengalami } \\
\text { kerusakan atau putus } \\
\text { akibat failure. }\end{array}$ & $\begin{array}{l}\text { Manual book } \\
\text { Dan Teknisi }\end{array}$ \\
\hline 2 & $\begin{array}{l}\text { Pergantian } \\
\text { roda gigi } \\
\text { yang } \\
\text { rusak. }\end{array}$ & $\begin{array}{l}\text { Pergantian roda gigi } \\
\text { apabila roda gigi } \\
\text { rusak jika teriadi } \\
\text { retak pada roda gigi }\end{array}$ & $\begin{array}{c}\text { Manual book } \\
\text { Dan teknisisi }\end{array}$ \\
\hline 3 & $\begin{array}{l}\text { Pergantian } \\
\text { jarring } \\
\text { pengaman } \\
\text { yang rusak }\end{array}$ & $\begin{array}{lr}\text { Pergantian } & \text { jarring } \\
\text { pengaman } & \text { yang } \\
\text { rusak } & \text { akibat } \\
\text { kerusakan } & \end{array}$ & $\begin{array}{l}\text { Manual book } \\
\text { dan Enginner }\end{array}$ \\
\hline
\end{tabular}

\section{KESIMPULAN}

Dari hasil dan pembahasan yang telah dilakukan pada bab sebelumnya, maka terdapat beberapa hal yang dapat disimpulkan yaitu:

1. Bahwa dalam Conveyor terdapat tiga peralatan kritis yaitu Rantai conveyor, Jaring baja dan Alur poros melintang. Pemilihan kekritisan peralatan tersebut didasarkan atas pengaruh failure terhadap pemenuhan target produksi dan frekuensi work order yang dilakukan pada peralatan tersebut.

2. Karena tingkat kehandalan yang rendah dan failure yang tinggi dari ketiga peralatan pada Conveyor tersebut diperlukan kegiatan preventive maintenance dan condition based maintenance yang lebih banyak untuk memastikan ketersediaan alat.

3. Berdasarkan fungsi, failure fungsi, sebab akibat failure, resiko failure, kegiatan perawatan yang berjalan dan ketersediaan data pada Conveyor. Dapat ditentukan dan dirancang aktivitas-aktivitas perawatan, yaitu, failure finding task.

\section{UCAPAN TERIMAKASIH}

Ucapan terimakasih kepada Jurusan Teknik Mesin, Politeknik Negeri Lhokseumawe yang telah memberikan bantuan dan fasilitas selama pelaksanaan penelitian ini.

\section{DAFTAR PUSTAKA}

A., C. (1992). Teknik Manajemen Pemeliharaan. Jakarta: Erlangga. 
Sariyusda, Analisis Reliability Centered Maintenance (RCM) Rel Conveyor pada Mesin Oven BTU Pyramax 150N di PT. Flextronics Teknology Indonesia - Batam

American Bureau of Shipping. (2003). Guide for Survey Based on Reliability Centered Maintenance. Houston: McGraw-Hill.

B, B. N. (2006). Reliability Centered Maintenance Implementation Made Simple. Houston: McGraw-Hill.

Daryus, A. (2007). Manajemen Pemeliharaan Mesin. Jakarta: Universtas Darma Persada.

Department of Defense United Stated of America. (1980). Procedures for Performing a Failure ModeEffecet and Critically Analysis. New York: UD Department of Defense.

Dhilon, B. (2006). Maintainability, Maintenance, and Reliability for Engineers. New York: Taylor and Francis Group.

Moubray, J. (1997). Reliability Centered Maintenance. London: Butterworth Heinemann Ltd.

Navaair. (2003). Management Manual Guidlines for The Naval Aviation Reliability Centered Maintenance Process. New York: Natec.

Stapelberg, R. F. (2009). Reliability, Availability, Maintanability and Safety ini Engineering Design. London: Springer-Verlag. 